\title{
Role of Proaggregatory and Antiaggregatory Prostaglandins in Hemostasis Studies with Combined Thromboxane Synthase Inhibition and Thromboxane Receptor Antagonism
}

\author{
Paolo Gresele, Jef Arnout, Hans Deckmyn, Enwin Huybrechts, Griet Pieters, and Jos Vermylen \\ Center for Thrombosis and Vascular Research, Department of Medical Research, University of Leuven, B-3000 Leuven, Belgium
}

\section{Abstract}

Thromboxane synthase inhibition can lead to two opposing effects: accumulation of proaggregatory cyclic endoperoxides and increased formation of antiaggregatory $\mathrm{PGI}_{\mathbf{2}}$ and $\mathrm{PGD}_{\mathbf{2}}$. The elimination of the effects of the cyclic endoperoxides by an endoperoxide-thromboxane $A_{2}$ receptor antagonist should enhance the inhibition of hemostasis by thromboxane synthase blockers. We have carried out a series of double-blind, placebo-controlled, crossover studies in healthy volunteers to check if this hypothesis may be operative in vivo in man.

In a first study, in $\mathbf{1 0}$ healthy male volunteers, the combined administration of the thromboxane receptor antagonist BM 13.177 and the thromboxane synthase inhibitor dazoxiben gave stronger inhibition of platelet aggregation and prolonged the bleeding time more than either drug alone. In a second study, in 10 different healthy male volunteers, complete inhibition of cyclooxygenase with indomethacin reduced the prolongation of the bleeding time by the combination BM 13.177 plus dazoxiben. In a third study, in five volunteers, selective cumulative inhibition of platelet TX $\mathbf{A}_{2}$ synthesis by low-dose aspirin inhibited platelet aggregation and prolonged the bleeding time less than the combination BM 13.177 plus dazoxiben.

In vitro, in human platelet-rich plasma stimulated with arachidonic acid, the combination of BM 13.177 and dazoxiben increased intraplatelet cAMP while the single drugs did not affect it.

Our results indicate that prostaglandin endoperoxides can partly substitute for the activity of $\mathrm{TXA}_{2}$ in vivo in man and that an increased formation of endogenous antiaggregatory and vasodilatory prostaglandins, as obtained with selective thromboxane synthase inhibitors, may contribute to the impairment of hemostasis.

\section{Introduction}

Thromboxane $\mathrm{A}_{2}\left(\mathrm{TXA}_{2}\right),{ }^{1}$ formed by human platelets through the sequential action of cyclooxygenase and throm-

Address reprint requests to Dr. Gresele, Istituto di Semeiotica Medica, University of Perugia, via E. dal Pozzo, I-06100 Perugia, Italy.

Parts of this work were presented at the International Conference on Leukotrienes and Prostanoids in Health and Disease, Tel Aviv, Israel, 20-25 October 1985, and at the 6th International Conference on Prostaglandins and Related Compounds, Florence, Italy, 3-6 June 1986.

Received for publication 7 October 1986 and in revised form 30 March 1987.

J. Clin. Invest.

(C) The American Society for Clinical Investigation, Inc.

$0021-9738 / 87 / 11 / 1435 / 11 \quad \$ 2.00$

Volume 80, November 1987, 1435-1445 boxane synthase, is a potent inducer of platelet aggregation and a strong vasoconstrictor (1). The last decade has witnessed a large effort in the search and testing of drugs blocking the formation or the activity of $\mathrm{TXA}_{2}$.

Cyclooxygenase inhibitors, among which is aspirin, induce a mild hemostatic defect after administration to man, as indicated by prolongation of the skin bleeding time, and have shown some antithrombotic activity in the clinic (2). However, the simultaneous inhibition of endothelial cyclooxygenase by aspirin represents a theoretical limitation to its antithrombotic activity as it would block the synthesis of prostacyclin (prostaglandin $\mathrm{I}_{2}, \mathrm{PGI}_{2}$ ), a potent vasodilator and a strong inhibitor of platelet aggregation (3).

Thromboxane synthase inhibitors administered to normal humans increase $\mathrm{PGI}_{2}$ formation two to three times (4), most probably as a consequence of the transfer of accumulating platelet endoperoxides to the endothelial cells that utilize them for the synthesis of $\mathrm{PGI}_{2}(5,6)$; a slight prolongation of the bleeding time is simultaneously observed (4). Thromboxane synthase inhibition also increases the formation of $\mathrm{PGF}_{2 \alpha}$, $\mathrm{PGE}_{2}$, and $\mathrm{PGD}_{2}$ by activated platelets; the last two can influence platelet reactivity (7). However, a possible drawback of thromboxane synthase inhibitors is related to the accumulation of cyclic endoperoxides that can occupy and activate the platelet and vessel wall $\mathrm{TXA}_{2}$ receptor and thus partly eliminate the benefit of suppressing $\mathrm{TXA}_{2}$ formation. This phenomenon has been proposed as an explanation for the weak and unequal effect of this class of compounds on platelet aggregation (8) and for the discouraging results of the preliminary trials in clinical conditions (9).

Thromboxane receptor antagonists have recently become available for use in man (10-12). These drugs have the potential advantage of impeding the action of TXA $\mathrm{A}_{2}$ simultaneously at the platelet and vessel wall levels and of antagonizing the effects of PG endoperoxides that act on a common $\mathrm{TXA}_{2} / \mathrm{PG}$ endoperoxide receptor; moreover, they would not interfere with $\mathrm{PGI}_{2}$ formation by the vessel wall. These drugs prolong the bleeding time, indicating an effect on primary hemostasis $(10,11)$, and preliminary studies seem to indicate that thromboxane receptor antagonism can normalize the altered indexes of platelet activation in atherosclerotic subjects (13). However, possible drawbacks of this class of compounds are represented by their competitive nature $(10,14)$, which could lead to their displacement from receptors by exceedingly high amounts of $\mathrm{TXA}_{2}$ generated at localized sites of platelet activation; by the fact that they do not increase endogenous $\mathrm{PGI}_{2}$ formation and

1. Abbreviations used in this paper: AA, arachidonic acid; BM 13.177, (2-[benzene-sulphonamido]-ethyl)-phenoxyacetic acid); dazoxiben, (4-[2-(IH-imidazol-1-yl)ethoxy]benzoic acid hydrochloride); GCNICI-MS, gas chromatography-negative ion chemical ionization-mass spectrometry; PFP, platelet-free plasma; $\mathrm{PG}$, prostaglandin; $\mathrm{PGI}_{\mathbf{2}}$, prostaglandin $\mathrm{I}_{2}$, prostacyclin; PRP, platelet-rich plasma; TAC, threshold aggregating concentration; $\mathrm{TXA}_{2}, \mathrm{TXB}_{2}$ : thromboxane $\mathrm{A}_{2}, \mathrm{~B}_{2}$. 
by the lack of activity on platelet activation induced byTXA independent agonists, such as high-dose collagen or thrombin.

Theoretically, the combination of a thromboxane synthase inhibitor with a thromboxane receptor antagonist may provide a solution to the limitations of both compounds. Indeed, the synthase inhibitor would increase the formation of antiaggregatory and vasodilatory prostaglandins $\left(\mathrm{PGI}_{2}\right.$ and $\left.\mathrm{PGD}_{2}\right)$ while the receptor antagonist would neutralize the platelet and vessel wall stimulatory activity of accumulated PG endoperoxides. The antagonism of mediators that decrease platelet cyclic AMP (cAMP) (TXA, PG endoperoxides), combined to the enhanced formation of products stimulating adenylate cyclase $\left(\mathrm{PGI}_{2}, \mathrm{PGD}_{2}\right)(15,16)$, might result in a net increase in cAMP in activated platelets. A rise in cAMP counteracts the aggregation induced by whatever stimulus (17), thus potentially reducing both $\mathrm{TXA}_{2}$-dependent and -independent platelet activation.

Evidence for a mutual potentiation of thromboxane synthase inhibitors and thromboxane receptor antagonists has already been obtained in vitro $(9,18,19)$. We have now studied the effect of dazoxiben (4-[2-(IH-imidazol-1-yl)ethoxy]benzoic acid hydrochloride), a thromboxane-synthase inhibitor (20), of BM 13.177 (2-[benzene-sulphonamido]-ethyl)phenoxyacetic acid), a thromboxane-receptor antagonist (10), and of their combination on platelet function, bleeding time and platelet prostaglandin production in normal man in three different randomized, double-blind, placebo-controlled studies. Evaluation of the pharmacodynamic interactions between these two drugs and the comparison of these results with those obtained in parallel by the administration of cyclooxygenase inhibitors should provide insights into $(a)$ the role of PG endoperoxides in vivo, $(b)$ the possible importance of increased endogenous formation of antiaggregatory prostaglandins, (c) the antithrombotic potential of such a combination.

\section{Methods}

Design of the studies. Three different investigations were carried out. In study $\mathrm{A}, 10$ healthy male nonsmokers (mean age $26.5 \mathrm{yr}$, range 22 to 40 ; mean weight $68.6 \mathrm{~kg}, 57-90$; and mean height $178 \mathrm{~cm}, 165-187$ ) participated in a double-blind, placebo-controlled, crossover study. Each subject received five treatments, in a balanced, randomized order. Study days were separated from each other by at least $48 \mathrm{~h}$, an interval that would exclude carryover effects on the basis of the known biological half-lives of the drugs $(9,10,20,21)$ and of previous experience (22). In addition, the problem of the possible interference of the sequential treatments with one another was examined by including two randomly located placebo groups. All volunteers received the following combinations: (2-[benzene-sulphonamido]-ethyl)-phenoxyacetic acid (BM 13.177) $800 \mathrm{mg}$ plus placebo (lactose); placebo plus dazoxiben $200 \mathrm{mg}$; BM $13.177800 \mathrm{mg}$ plus dazoxiben $200 \mathrm{mg}$; placebo plus placebo (twice), each administered as two tablets and two capsules, identical and unlabeled. Venous blood samples were taken by the free-flow technique, $3 \mathrm{~h}$ after intake of BM 13.177 (1 h after dazoxiben). This moment of sampling was selected to coincide with reported peak plasma levels of the drugs $(10,20-22)$. Blood pressure and heart rate were then measured followed by bleeding time determinations.

In study B, 10 different male volunteers (mean age $24.8 \mathrm{yr}$, range, 22-36; mean weight $71.4 \mathrm{~kg}, 61-78$; and mean height $181 \mathrm{~cm}$, 173-187) were enrolled in a study with the same characteristics of study A except that this time on each study day the volunteers received a combination of three drugs. The five following treatments were given, in a balanced, randomized order: BM 13.177, $800 \mathrm{mg}$ plus dazoxiben, $200 \mathrm{mg}$ plus placebo; placebo plus indomethacin $100 \mathrm{mg}$ plus placebo; BM $13.177800 \mathrm{mg}$ plus dazoxiben $200 \mathrm{mg}$ plus indomethacin $100 \mathrm{mg}$; placebo plus placebo plus placebo (twice). BM 13.177 was ingested $3 \mathrm{~h}$ before the tests and dazoxiben and indomethacin $1 \mathrm{~h}$ before the tests.

In study C, 5 different male volunteers (mean age 26.4 yr, 21-38; mean weight $70.3 \mathrm{~kg}, 61-86$; and mean height $179 \mathrm{~cm}, 173-186)$ were treated with aspirin (capsules prepared by directly weighing acetylsalicylic acid) in daily doses of $0.43 \pm 0.02 \mathrm{mg} / \mathrm{kg}$ per $\mathrm{d}$ for 10 consecutive days. The volunteers were very carefully instructed about the aims of the study to enhance compliance; in addition, capsules were counted on each study day to check for regular drug intake. Blood samples were taken before the intake of the first capsule, $1 \mathrm{~h}$ later and on the 4th, 8th and 10th d of treatment $1 \mathrm{~h}$ after dosing. Bleeding times were measured before starting the treatment and on the 10th day $1 \mathrm{~h}$ after aspirin intake. After a washout period of 3 wk the five volunteers were randomized to receive BM $13.177800 \mathrm{mg}$ plus placebo, BM 13.177800 $\mathrm{mg}$ plus dazoxiben $200 \mathrm{mg}$ or placebo plus placebo, on three different days separated from each other by at least $48 \mathrm{~h}$. The sequence of treatments was randomized and they were administered by the investigators in a double blind way. Finally, after an additional 48 -h washout, the volunteers were given BM $13.1771,600 \mathrm{mg}$, and after $2 \mathrm{~d}$, aspirin $500 \mathrm{mg}$. The tests were carried out $3 \mathrm{~h}$ after BM 13.177 and $1 \mathrm{~h}$ after aspirin intake. Although low-dose aspirin, high-dose aspirin and BM $13.1771,600 \mathrm{mg}$ were given under unblinded conditions, the operator performing the bleeding time and the person carrying out the platelet aggregation studies were unaware of the treatment given.

The safety of the combination of BM 13.177 and dazoxiben was tested in a pilot study on four volunteers (chosen among the authors of this paper). Physical examinations and full blood and platelet count, urinalysis, serum glutamic oxaloacetic acid transaminase, serum glutamic pyruvic transaminase, uric acid, blood urea nitrogen, and serum creatinine before and at various intervals (up to $1 \mathrm{wk}$ ) after the combined intake of the two compounds were unchanged. No subjective side effects were reported.

The studies were carried out according to the principles of the Declaration of Helsinki and were approved by the Ethical Committee of our Institution. Informed, written consent was given by all volunteers. Subjects were not accepted in the studies if they had taken whatever drugs during the two weeks preceding enrollment; they were instructed to keep their feeding habits, alcohol intake and physical activity constant throughout the studies. All tests were carried out in the morning in fasting conditions. The double blind code of the studies was not broken until the biochemical analyses, except $\mathrm{PGD}_{2}$ assay, were completed. All drugs were administered by the investigators.

Platelet aggregation studies. Aggregation was studied in plateletrich plasma (PRP) with the optical method (23) using an Elvi 840 dual channel aggregometer (Elvi Logos, Milan, Italy) as previously described (24). The threshold aggregating concentrations (TAC) of various inducers were determined; these were defined as the minimal concentration of the stimulus giving full, irreversible aggregation (more than 60\% light transmission), starting within two min from the addition of the inducer for collagen and arachidonic acid. ADP-induced aggregation had to include a second wave and/or to be irreversible for at least $5 \mathrm{~min}$ (24). When the TAC exceeded $5 \mathrm{mM}$ for arachidonic acid, $5 \mu \mathrm{M}$ for $\mathrm{U} 46619$ and $20 \mu \mathrm{g} / \mathrm{ml}$ for collagen it was arbitrarily assigned these values for statistical analysis. The following inducers were used: arachidonic acid, sodium salt (AA) (> 99\% pure, Sigma Chemical Co., St. Louis, MO), the stable endoperoxide analogue U46619 (9,11-dideoxy-1 $1_{\alpha}, 9_{\alpha}$-epoxymethano-prostaglandin $\mathrm{F}_{2 \alpha}$ ) (Upjohn, Kalamazoo, MI), collagen (Hormon-Chemie, Munich, West Germany) and adenosine diphosphate (ADP) (Sigma Chemical Co.). A stock solution of ADP, U46619 and AA was prepared before each study, frozen at $-20^{\circ} \mathrm{C}$ in separate aliquots and used throughout the study to ensure maximal reproducibility. Dilutions of the collagen stock solution were freshly prepared on each study day. Aggregation studies were carried out between $\mathbf{4 0}$ and $70 \mathrm{~min}$ after venipuncture.

Blood was collected from all donors before the beginning of each study and the effect of dazoxiben (100 $\mu \mathrm{M}$ final concentration), prein- 
cubated with platelets for $1 \mathrm{~min}$, was tested on the aggregation induced by AA at the TAC, as previously described (7). "Responders" were defined as those subjects in whom after incubation with dazoxiben no aggregation was observed within 2 min after AA addition.

Platelet aggregation was also studied in whole blood by the impedance method (25), using a Chrono-Log 540 dual channel whole blood aggregometer (Chrono-Log Corp., Havertown, PA), as previously described (24). Collagen $0.5,1,3$, and $5 \mu \mathrm{g} / \mathrm{ml}$ and ADP $1,2,5$, and 10 $\mu \mathrm{M}$ were used as inducers. Aggregation was followed for $9 \mathrm{~min}$ and the maximal amplitude, expressed in ohms $(\Omega)$, was calculated. To increase the reproducibility of the results the following precautions were taken: aggregation studies were carried out between 20 and $80 \mathrm{~min}$ after blood collection, the period of maximal stability of platelet reactivity in whole blood (Gresele et al., unpublished observations); each inducer was always tested in the same aggregometer channel and using the same electrode; the sequence in which the four concentrations of the inducers were tested was kept constant; the agonists were injected, in volumes not $>10 \mu \mathrm{l}$, at the bottom of the blood samples using Hamilton syringes and taking care to avoid disturbing the electrodes; the calibration of the instrument was carefully performed before each platelet aggregation study and only after a perfectly stable base-line was obtained; whenever erratic movements of the recorder pen were observed during the equilibration and calibration period, the platinum electrodes were extracted from the sample, energetically rinsed with a stream of isotonic saline and placed back into the sample; if even after this procedure a stable baseline was not obtained, the sample was discarded and the full procedure repeated; blood samples were kept at room temperature in tightly capped plastic tubes and periodically mixed gently to avoid spontaneous sedimentation of red cells; the last 2 $\mathrm{ml}$ of each test tube were not used for aggregation studies.

Measurement of thromboxane $B_{2}$ and prostaglandins. Immunoreactive $\mathrm{TXB}_{2}$ in serum (26) was measured by a specific radioimmunoassay (RIA), as previously described (27). Briefly, unextracted serum samples were diluted with the assay buffer (Tris- $\mathrm{HCl}$ buffered isotonic saline, $\mathrm{pH} 7.5)$ at three different dilutions (1:10, 1:50, and 1:250). The final volume of the assay mixture, which comprised $\sim 10,000 \mathrm{cpm}$ of radiolabeled $\left[{ }^{3} \mathrm{H}\right] \mathrm{TXB}_{2}$ (sp act $180 \mathrm{Ci} / \mathrm{mM}$; Amersham International, Amersham, England) and a specific rabbit anti-TXB ${ }_{2}$ antiserum (kindly provided by Dr. L. Levine, Brandeis University, Waltham, MA) diluted 1:50,000 in assay buffer, was $200 \mu$ l giving a final dilution for the samples of 1:20, 1:100, and 1:500.50\% displacement for unlabeled $\mathrm{TXB}_{2}\left(\mathrm{IC}_{50}\right)$ was at $630.1 \pm 40.1 \mathrm{pg} / \mathrm{ml}(n=5)$ and the least detectable amount ( 2 SD from zero) was $35 \mathrm{pg} / \mathrm{ml}$, giving a detection limit of $0.7 \mathrm{ng}$ of $\mathrm{TXB}_{2}$ per $\mathrm{ml}$ of serum. Cross-reactivities of the antiserum have been reported $(27,28)$.

6-keto-PGF ${ }_{1 \alpha}$ levels, the stable metabolite of $\mathrm{PGI}_{2}$, were measured in the capillary blood emerging from the skin bleeding time wound: after a drop of blood had formed on top of the skin incisions a capillary tube was immersed into it, taking care to avoid touching the edges of the wound, and blood was collected by capillarity. Heparinized hematocrit capillaries ( $75 \mu \mathrm{l}$ vol) that had been flushed with a $1: 1 \mathrm{vol} / \mathrm{vol}$ mixture of sodium heparin $5,000 \mathrm{U} / \mathrm{ml}$ and lysine acetylsalicylic acid $0.55 \mathrm{M}$, were used. Two to four such capillaries were filled with blood in the period between $30 \mathrm{~s}$ and $2 \mathrm{~min}$ from the moment of incision. The tubes were immediately centrifuged at $6,000 \mathrm{~g}$ for $5 \mathrm{~min}$, broken at $0.5 \mathrm{~cm}$ from the plasma to erythrocyte interface and the cell-free supernatant extruded and stored at $-20^{\circ} \mathrm{C}$ until assayed. Blood anticoagulation was checked by carrying out a thrombin clotting time on the plasma: no clot formation was observed. Each sample was assayed in duplicate using a modification of the RIA for 6-keto-PGF $1 \alpha$ previously described (27). The final volume of the assay mixture was $75 \mu \mathrm{l}$, and 25 $\mu \mathrm{l}$ of the unextracted samples were used. 50\% displacement of 6-keto$\mathrm{PGF}_{1 \alpha}$ was at $1385 \pm 53 \mathrm{pg} / \mathrm{ml}(n=4)$, while the least detectable amount was $100 \mathrm{pg} / \mathrm{ml}$. The anti-6-keto-PGF $1 \alpha$ serum, kindly provided by Dr. J. Beetens (Janssen Pharmaceutica, Beerse, Belgium), was used at a dilution of 1:6,600; it was highly specific displaying the following cross-reactivities: $\mathrm{PGE}_{2}=0.6 \%, \mathrm{PGF}_{2 \alpha}=0.4 \%, \mathrm{PGD}_{2}$ $=0.1 \%, 13,14$-dihydro-PGF $2 \alpha<0.1 \%, \mathrm{TXB}_{2}<0.1 \%$.
Eicosanoids produced by AA-stimulated PRP were also determined, as previously described (7). The TAC selected during the screening test carried out before enrollment was maintained constant for each volunteer throughout the study. $\mathrm{TXB}_{2}$ was measured on unextracted plasma essentially as described for serum. Final dilutions for the $\mathrm{TXB}_{2}$ assay were 1:20 to 1:2000. Cross-reactivity of the anti-TXB serum with AA ( $>99 \%$ pure) was $<0.00005 \%$.

A commercial RIA kit was used for the PGE $_{2}$ assay (NEK-020A, New England Nuclear, Boston, MA) that utilizes ${ }^{125} \mathrm{I}-\mathrm{PGE}_{2}$ as tracer. Final dilutions of the plasma samples in this assay were 1:300, 1:3,000, and $1: 30,000 ; \mathrm{IC}_{50}$ for unlabeled $\mathrm{PGE}_{2}$ was $31.4 \pm 2.3 \mathrm{pg} / \mathrm{ml}(n=3)$ and the least detectable amount was $2.5 \mathrm{pg} / \mathrm{ml}$ giving a detection limit of $750 \mathrm{pg} / \mathrm{ml}$. The anti-PGE ${ }_{2}$ serum used has a cross-reactivity with AA far below $0.01 \%$ and with $\mathrm{PGD}_{2}$ lower than $0.001 \%$ thus excluding interference with the assay; cross-reactivity with $\mathrm{TXB}_{2}$ was $<0.02 \%$ thus allowing reliable determinations of this PG, even in the presence of three orders of magnitude higher concentrations of $\mathrm{TXB}_{2}$ in the same samples.

$\mathrm{PGD}_{2}$ was assayed in a subgroup of samples from study A: eight samples from both placebo 1 and dazoxiben groups and four samples from both placebo 2 and dazoxiben plus BM 13.177 groups, randomly selected. The $\mathrm{PGD}_{2}$-immunoreactive material was measured in $\mathrm{AA}$ $($ TAC $\times 2$ )-stimulated PRP samples, as follows: $90 \mu \mathrm{l}$ plasma was acidified to $\mathrm{pH} 3.0$ with $225 \mu$ l citric acid $0.1 \mathrm{~N}$ and then extracted three times with $1 \mathrm{ml}$ diethylether saturated with water. The pooled organic phases were dried under vacuum in a Speed Vac Concentrator (Savant Instruments Inc., Hicksville, NY) and redissolved in Tris- $\mathrm{HCl}$ buffer $50 \mathrm{mM}, \mathrm{pH} 8.6$, containing $0.1 \%$ gelatine. Recovery was $61.1 \pm 1.5 \%(n=13)$. The redissolved samples $(100 \mu \mathrm{l})$ diluted to $1: 4$ and 1:40, were mixed with $\sim 5,000 \mathrm{cpm}$ of radiolabeled $\left[{ }^{3} \mathrm{H}\right] \mathrm{PGD}_{2}$ (Amersham International, Amersham, England) and with a specific anti-PGD ${ }_{2}$ serum (purchased from Dr. L. Levine, Brandeis University, Waltham, MA) diluted 1:100 in Tris-HCl-gelatine buffer, to a final volume of $300 \mu \mathrm{l}$. The incubation was carried out at $4^{\circ} \mathrm{C}$ for $18 \mathrm{~h}$ and free and antibody-bound ${ }^{3} \mathrm{H}$-ligand were separated by precipitation with an equal volume of dextran-coated charcoal. The supernatant was counted for radioactivity. All procedures were carried out at $4^{\circ} \mathrm{C}$. $50 \%$ binding for $\mathrm{PGD}_{2}$ was at $1,140 \pm 100 \mathrm{pg} / \mathrm{ml}(n=5)$, the least detectable amount was $200 \mathrm{pg} / \mathrm{ml}$ giving a detection limit of $2.4 \mathrm{ng} / \mathrm{ml}$. Crossreactivities of this antiserum with a number of other PGs have been

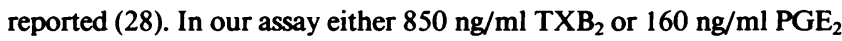
added to a PG-free plasma sample gave $<10 \%$ inhibition of $\mathrm{PGD}_{2}$ binding, while AA ( $>99 \%$ pure) cross-reacted $<0.000001 \%$, indicating that in the described conditions only endogenously produced $\mathrm{PGD}_{2}$ can account for the observed immunoreactivity. Various amounts (from 0 to $20 \mathrm{ng} / \mathrm{ml}$ ) of standard PGD $_{2}$ (Upjohn Co., Kalamazoo, MI) added to PG-free plasma were recovered quantitatively $(r$ $=0.98, P<0.005$ ).

Bleeding times. Bleeding times were determined in duplicate, two cuts on each forearm, using an automatic template device (Simplate II, General Diagnostics, Morris Plains, NJ). The incisions were placed in the longitudinal direction on the volar surface of the upper forearm. The mean bleeding time was calculated from the four different cuts; whenever one of the four values was $>2$ SD removed from the mean of the other three measurements it was eliminated. This was the case for 2 out of 50 determinations in study A, for 3 out of 50 in study B and for 2 out of 35 for study C; the elimination procedure was carried out before the code was broken. When the measured bleeding time exceeded 30 min it was arbitrarily assigned the value of $30 \mathrm{~min}$ for statistical analysis. The same operator carried out all the bleeding time determinations throughout the three studies in the same room with a relatively constant temperature.

Assay of cAMP formation in platelets. The levels of metabolically responsive cAMP in platelets were measured radiochemically. Human PRP, anticoagulated with disodium EDTA, was incubated at $37^{\circ} \mathrm{C}$ for 30 min with $0.565 \mu \mathrm{M}\left[{ }^{3} \mathrm{H}\right]$ adenine $(17.7 \mathrm{Ci}$ per $\mathrm{mmol}$ ) (New England Nuclear). Unincorporated $\left[{ }^{3} \mathrm{H}\right]$ adenine was removed by centrifugation of the PRP at 2,000 $\mathrm{g}$ for $10 \mathrm{~min}$ and disposal of the supernatant PPP. 
The $\left[{ }^{3} \mathrm{H}\right]$ adenine-loaded platelets were then resuspended in autologous citrated PPP and left to recover for $20 \mathrm{~min}$ at room temperature. Different compounds in microliter quantities were added to $0.5-\mathrm{ml}$ aliquots of resuspended platelets; the samples were briefly mixed and incubated at $37^{\circ} \mathrm{C}$ for various periods. Addition of $50 \mu \mathrm{l}$ of $0.306 \mathrm{M}$ TCA, containing around $7,400 \mathrm{cpm}$ and $2.2 \mu \mathrm{M}$ of $\left[{ }^{14} \mathrm{C}\right] \mathrm{cAMP}$ (Sigma Chemical Co.), and vigorous shaking terminated the incubations. $\left[{ }^{14} \mathrm{C}\right]$ cAMP was added for determination of recovery. The samples were then centrifuged at $12,000 \mathrm{~g}$ for $5 \mathrm{~min}$ to remove precipitated proteins, and the $\left[{ }^{3} \mathrm{H}\right]$ cAMP was isolated by chromatography on 2-ml Dowex AG 50W-X4, 100 to 200 mesh size (Bio-Rad Laboratories, Richmond, CA) columns. Further purification was obtained by treating the samples with $0.266 \mathrm{M} \mathrm{ZnSO}_{4}$ and $0.266 \mathrm{M} \mathrm{Ba}(\mathrm{OH})_{2}$ (29). All separation procedures were carried out at $22^{\circ} \mathrm{C}$.

Plasma and serum levels of the experimental drugs. Plasma levels of dazoxiben were measured by high-performance liquid chromatography and UV detection at $250 \mathrm{nM}$ (30). The detection limit was at 10 $\mu \mathrm{g} /$ liter. Serum levels of BM 13.177 were estimated by gas liquid chromatography using BM 13.235 (2-[4-(2-((4-chloro-1-naphtalenylcarbonyl)amino)ethyl)phenoxy]-2-methyl-propionic acid) as an internal standard (21). The detection limit of the assay was at $0.2 \mathrm{mg} / \mathrm{liter}$.

Statistical analysis. Two-way analysis of variance followed by Tukey's multiple comparison test for all pairs (31) was applied to evaluate the difference between the results obtained after the various treatments. For some selected experiments the two-tailed Student's $t$ test for paired data was used, as indicated. The correlation between various parameters was assessed by linear regression analysis. All values are given as mean \pm SEM.

\section{Results}

Study $A$. The bleeding time was significantly prolonged by both dazoxiben and BM 13.177 intake. BM 13.177 induced a $65 \%$ increase in bleeding time, which was significantly more than the $44 \%$ increase induced by dazoxiben $(P<0.005)$. The combination of the two drugs gave a $93 \%$ prolongation, which was significantly more than the bleeding time measured after each of the two drugs separately (Fig. 1). The bleeding times measured after the intake of the two placebos did not differ. No differences in hematocrit values nor in platelet counts were observed after the different treatments.

The combined intake of dazoxiben and BM 13.177 inhibited AA- and collagen-induced platelet aggregation significantly more than the single drugs (Fig. 2). AA-induced platelet aggregation was completely suppressed in all but one volunteer after the combined intake of dazoxiben and BM 13.177.

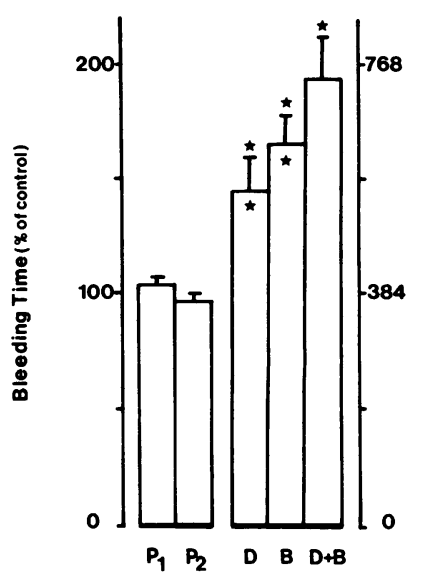

Figure 1. Bleeding time after the intake of the various treatments (study A). P1, placebo 1; P2, placebo 2; D, dazoxiben $200 \mathrm{mg}$; , BM $13.177800 \mathrm{mg}$; D + B $=$ dazoxiben, $200 \mathrm{mg}$ plus BM $13.177800 \mathrm{mg}$. Stars outside the columns mean significantly different from placebo (significances reported only when simultaneously different from both placebos) $(P<0.0005)$; stars inside the columns mean significantly different from $\mathrm{D}+\mathrm{B}(P<0.01$, at least).
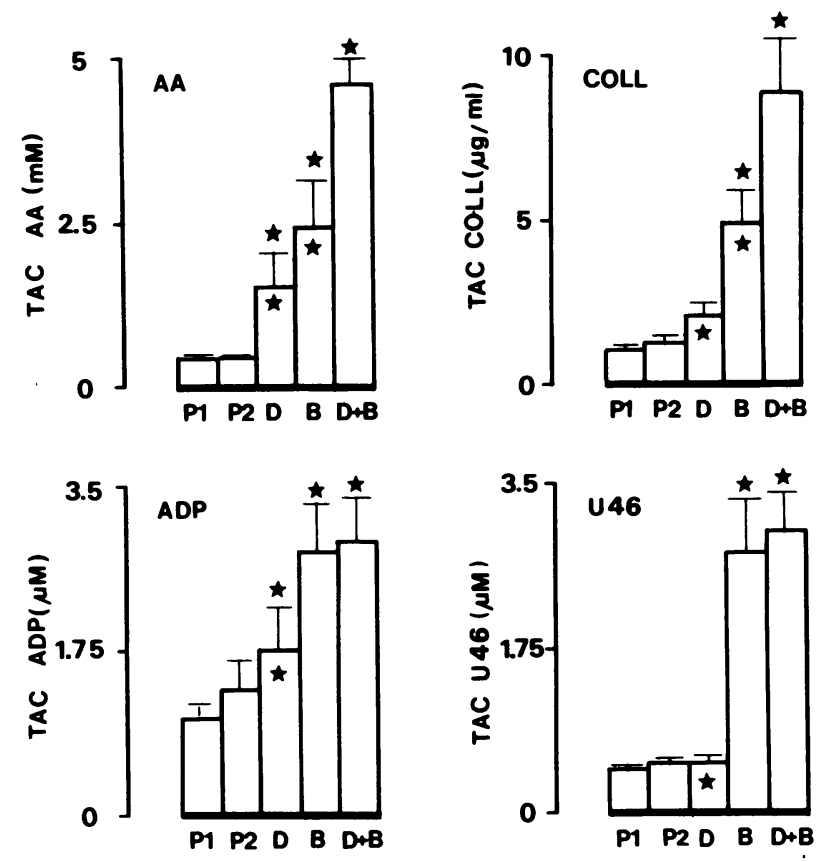

Figure 2. Threshold aggregating concentration (TAC) in PRP for arachidonic acid (AA), collagen (coll), ADP, and U46619 (U46) after the intake of the various treatments (study A). Symbols as in Fig. 1. $(\star P<0.0005$ except for the differences between dazoxiben and placebo, where $P<0.01$ ). Only the second wave of ADP-aggregation was inhibited by the various treatments.

In whole blood too, when using the two highest doses of collagen, against which dazoxiben or BM 13.177 used alone exert only a marginal or no inhibition, a clear increase of the inhibitory effect was observed after the combined intake (Fig. 3). ADP-induced platelet aggregation in whole blood was not more inhibited after BM 13.177 plus dazoxiben intake than after BM 13.177 intake, whatever the concentration of the inducer (Fig. 3).

Serum $\mathrm{TXB}_{2}$ was suppressed by around $90 \%$ after dazoxiben or after the combined intake of dazoxiben and BM 13.177. $\mathrm{TXB}_{2}$ values fell from $182 \pm 14$ and $187 \pm 9 \mathrm{ng} / \mathrm{ml}$ (placebo 1 and 2 , respectively) to $25.3 \pm 12 \mathrm{ng} / \mathrm{ml}$ after dazoxiben and to $22.9 \pm 9 \mathrm{ng} / \mathrm{ml}$ after dazoxiben plus BM 13.177. No inhibition of $\mathrm{TXB}_{2}$ formation was observed after BM 13.177 (Fig. 4a).

6 -Keto- $\mathrm{PGF}_{1 \alpha}$-immunoreactive material in capillary blood was $301 \pm 38$ and $420 \pm 57 \mathrm{pg} / \mathrm{ml}$ after the intake of placebo 1 and 2, respectively. This difference was not statistically significant. BM 13.177 intake did not change 6-keto-PGF ${ }_{1 \alpha}$ levels while both after dazoxiben and after dazoxiben plus BM 13.177 intake a significant increase was observed that varied, in individual cases, from a 1.7- to an 8.5-fold increase. The increase observed after the combination was slightly, but significantly, lower than that seen after dazoxiben alone (Fig. $4 a$ ).

$\mathrm{TXB}_{2}$ production by PRP stimulated with $\mathrm{AA}$ at the TAC was suppressed after dazoxiben intake (by $76 \%$ ) but it was also significantly reduced after BM 13.177 administration (by 53\%). When PRP was stimulated with a higher AA concentration $(\mathrm{TAC} \times 2)$ only dazoxiben suppressed $\mathrm{TXB}_{2}$ formation (by $83 \%$ ). The effect of the combination did not differ significantly from that of dazoxiben alone ( $92 \%$ inhibition) (Fig. $4 b$ ). Dazoxiben intake increased $\mathrm{PGE}_{2}$ formation significantly 

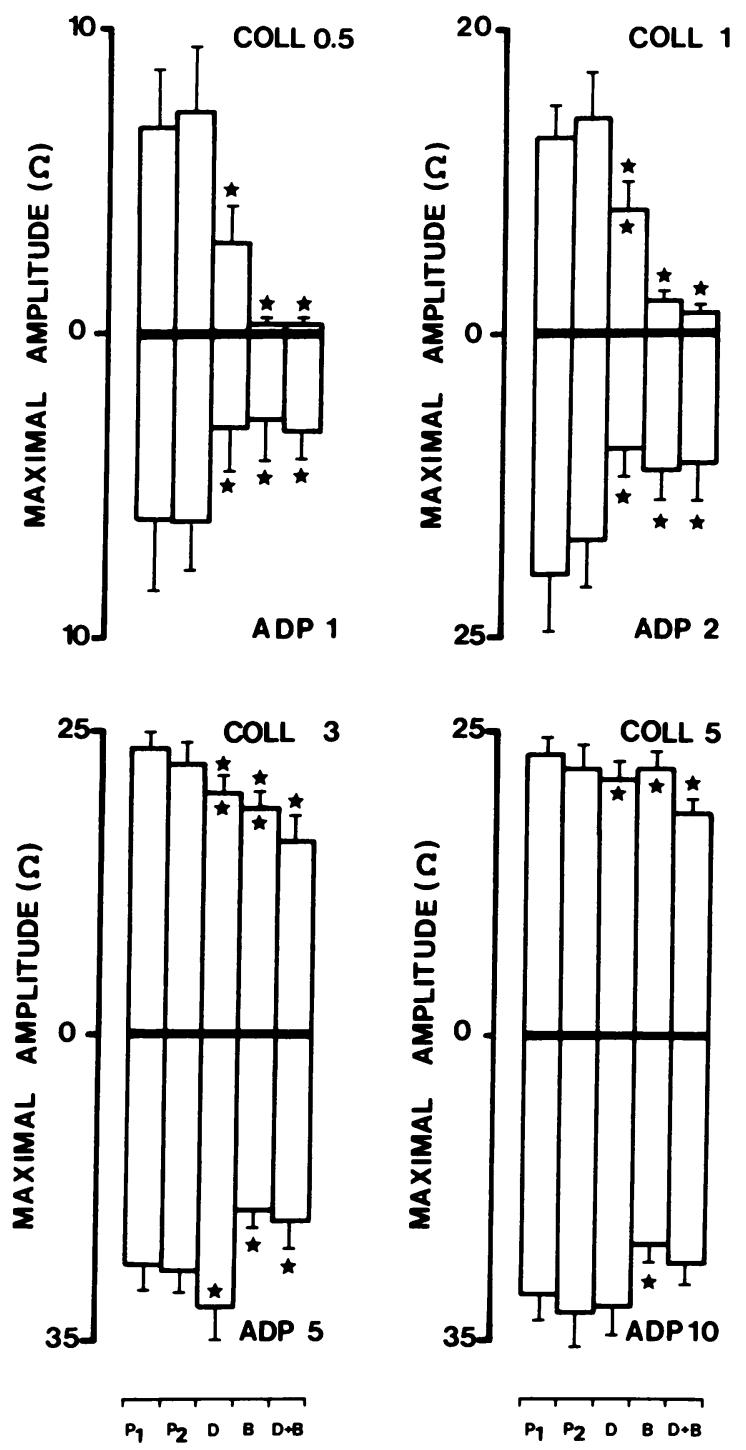

Figure 3. Maximal amplitude of aggregation induced in whole blood by various concentrations of collagen $(\mu \mathrm{g} / \mathrm{ml})$ and ADP $(\mu \mathrm{M})$ after the intake of the various treatments (study A). Symbols as in Fig. 1. $(\star P<0.05$, at least).

when twice the TAC of AA was used as a stimulus. A significant $\mathrm{PGE}_{2}$ increase was observed also after $\mathrm{BM} 13.177$ plus dazoxiben intake, although slightly less evident than after dazoxiben alone (Fig. $4 \mathrm{~b}$ ). $\mathrm{PGD}_{2}$ production after stimulation with AA at twice the TAC increased significantly both after dazoxiben and after dazoxiben plus BM 13.177 intake (Fig. 5).

The circulating levels of the drugs did not differ when taken alone or in combination (Table I). No side effects were reported; no treatment influenced blood pressure or heart rate.

A significant inverse correlation was found between the plasma levels of dazoxiben and the amount of $\mathrm{TXB}_{2}$ measured in serum $(r=0.49, n=20, P<0.05)$. Serum BM 13.177 directly correlated with the TAC of collagen $(r=0.70, n=10$, $P<0.05)$ and of U46619 $(r=0.86, n=10, P<0.01)$.

For all the above discussed parameters no significant differences were observed when comparing the results obtained after the intake of the two placebos, thus indicating a satisfactory reproducibility of the tests and excluding drug effects per- sisting for longer than $48 \mathrm{~h}$. The latter was also confirmed by lack of any appreciable difference in the effects of the three active treatments when analyzed according to the preceding regimen.

Study B. The combination of BM 13.177 and dazoxiben again significantly prolonged the bleeding time. The increase, in this case, was $114 \%$ above the averaged values measured after placebo intake. The addition of $100 \mathrm{mg}$ indomethacin to the combination BM 13.177 plus dazoxiben lead to a significant shortening of the bleeding time, which was only $57 \%$ longer than the control value (Fig. 6). Indomethacin alone prolonged significantly the bleeding time $(+75 \%)$, but significantly less than the combination BM 13.177 plus dazoxiben.

Platelet aggregation was not more inhibited by the dazoxiben plus BM 13.177 treatment (which behaved as in study A) than by the indomethacin plus dazoxiben plus BM 13.177 treatment or the indomethacin treatment (data not shown).

Serum $\mathrm{TXB}_{2}$ was suppressed by $91 \%$ after dazoxiben plus BM 13.177 , by $97.7 \%$ by indomethacin alone and by $99.7 \%$ by the triple combination. $\mathrm{TXB}_{2}$ production by AA-stimulated PRP behaved similarly to serum $\mathrm{TXB}_{2}$, while the production of $\mathrm{PGE}_{2}$, which significantly increased after the combination of dazoxiben plus BM 13.177, was suppressed by indomethacin $(-93 \%)$ or by indomethacin plus dazoxiben plus BM 13.177 intake $(-92 \%)$ (data not shown).

Dizziness and gastric discomfort were reported by $40 \%$ of the volunteers who took indomethacin (alone or in combination).

Study $C$. The bleeding time was significantly lengthened after the prolonged intake of low-dose aspirin. An $86 \%$ increase in bleeding time as compared to the pretreatment value (68\% as compared to the value measured after the subsequent placebo intake) was observed simultaneously with a $92 \%$ suppression of serum $\mathrm{TXB}_{2}$ (Fig. 7). In the same volunteers BM $13.177800 \mathrm{mg}$ induced a $66 \%$ prolongation of the bleeding time as compared with the basal ( $50 \%$ as compared to placebo) without any suppression of serum $\mathrm{TXB}_{2}$, while a high dose of aspirin $(500 \mathrm{mg})$, which induced an almost total suppression of serum $\mathrm{TXB}_{2}(99.7 \%)$, prolonged the bleeding time by $87 \%$ as compared with the basal value (69\% as compared to placebo intake). The combination of dazoxiben $200 \mathrm{mg}$ plus BM $13.177800 \mathrm{mg}$ prolonged the bleeding time by $121 \%$ as compared to pretreatment value ( $100 \%$ as compared with placebo), simultaneously with a $92 \%$ decrease in serum $\mathrm{TXB}_{2}$ (Fig. 7). The difference between the prolongation of the bleeding time obtained with the combination of dazoxiben plus BM 13.177 and that obtained with low-dose aspirin, high-dose aspirin or BM $13.177800 \mathrm{mg}$ alone was significant. No significant differences instead were found between low-dose aspirin vs. BM 13.177 or high-dose aspirin or between BM $13.177800 \mathrm{mg}$ vs. BM $13.1771,600 \mathrm{mg}$ (data not shown). The difference between the basal bleeding time and that measured blindly after placebo intake was not significant.

In PRP the combination of dazoxiben and BM 13.177 inhibited collagen, U46619 and ADP-induced platelet aggregation significantly more than low-dose aspirin, and the aggregation induced by collagen, AA and ADP significantly more than BM $13.177800 \mathrm{mg}$ alone (Table II). The differences between the combination and $500 \mathrm{mg}$ aspirin, however, failed to attain the level of significance, except for U46619-induced aggregation that was unaltered by aspirin. Selective antagonism of $\mathrm{TXA}_{2}$ action was not superior to the selective inhibi- 
a.

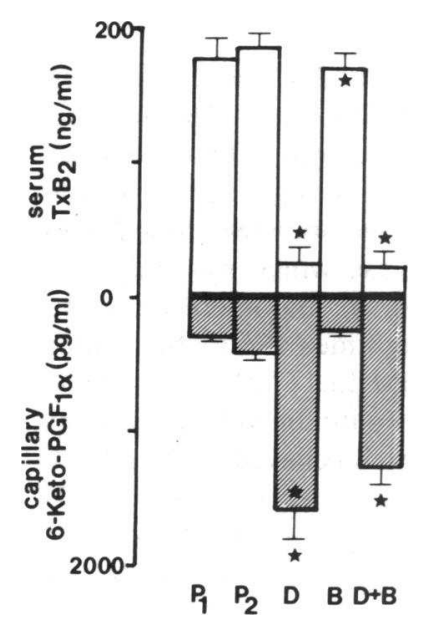

b.

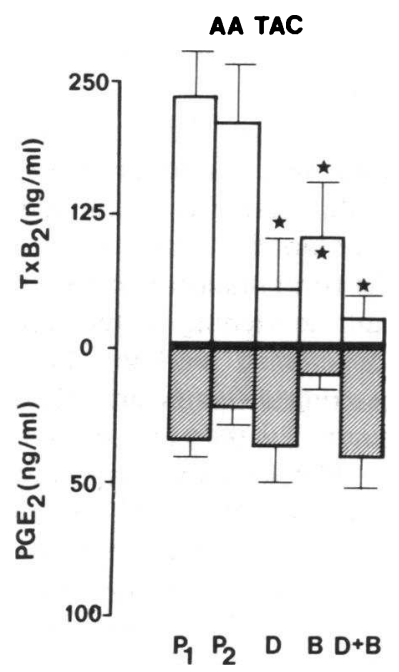

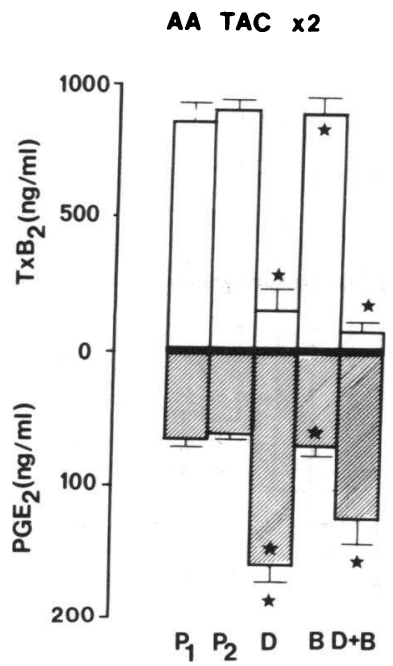

Figure 4. (a) Serum $\mathrm{TXB}_{2}$ and capillary blood 6-keto-PGF ${ }_{1 \alpha}$ after the intake of the various treatments (study A). Symbols as in Fig. 1. $\star P$ $<0.0005$ (significances reported only when simultaneously different from both placebos). (b) $\mathrm{TXB}_{2}$ and $\mathrm{PGE}_{2}$ produced by PRP stimulated with arachidonic acid at the TAC and at twice the TAC. Symbols as in Fig. $1 . \star P<0.01$, at least. tion of platelet $\mathrm{TXA}_{2}$ formation by low-dose aspirin when using ADP and collagen as inducers. However, low-dose aspirin completely suppressed AA-induced platelet aggregation while BM 13.177 significantly inhibited but did not suppress it; on the other hand, U46619-induced aggregation was strongly inhibited by BM 13.177 while it was unaffected by aspirin. A 1,600-mg dose of BM 13.177 inhibited the aggregation by $\mathrm{U} 46619$ and by AA significantly more than an $800-\mathrm{mg}$ dose, in agreement with the competitive nature of this antagonist $(10,14)$.

In whole blood the combination dazoxiben-BM 13.177 also suppressed platelet aggregation significantly more than low-dose aspirin or BM $13.177800 \mathrm{mg}$ when using collagen 1 and $3 \mu \mathrm{g} / \mathrm{ml}$. The aggregation induced by a high concentration of collagen $(5 \mu \mathrm{g} / \mathrm{ml})$ was significantly reduced only by dazoxiben plus BM 13.177 and by the high-dose of aspirin (Table III). ADP-induced platelet aggregation was not consistently more inhibited by the combination dazoxiben-BM 13.177 than by the other treatments (Table III).

$\mathrm{TXB}_{2}$ production by AA-stimulated PRP reproduced the data observed in study $A$; low-dose aspirin simultaneously suppressed $\mathrm{TXB}_{2}$ (by $98.3 \%$ ) and $\mathrm{PGE}_{2}$ production (by $82.5 \%$ ) (data not shown).

No consistent changes in blood pressure and heart rate were apparent with any of the treatments; all treatments were

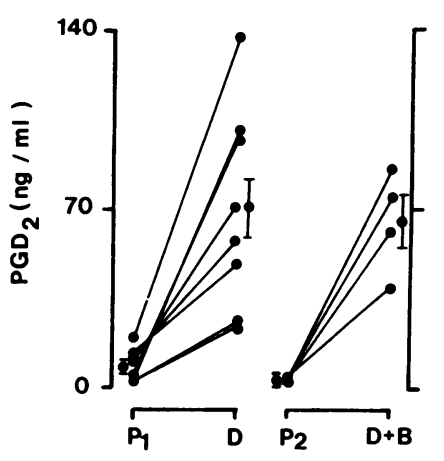

Figure 5. $\mathrm{PGD}_{2}$ produced by PRP stimulated with arachidonic acid, at twice the TAC, after the following treatments (study A): $P_{1}$, placebo $1 ; P_{2}$, placebo 2; D, dazoxiben 200 $\mathrm{mg} ; \mathrm{D}+\mathrm{B}=$ dazoxiben 200 mg plus BM $13.177800 \mathrm{mg}$. The increase in $\mathrm{PGD}_{2}$ was significant both after dazoxiben $(P<0.0025)$ and after dazoxiben plus BM $13.177(P$ $<0.005$ ) (Student's $t$ test for paired samples). well tolerated except for one episode of gastric discomfort after the intake of $500 \mathrm{mg}$ aspirin.

In vitro dazoxiben suppressed AA-induced platelet aggregation in three of 10 subjects of study A (responders), 5 of 10 of study B and 3 of 5 of study C. A trend toward a higher inhibition of platelet aggregation, both in PRP and in whole blood, and toward a greater prolongation of the bleeding time was present in the responders after treatment with dazoxiben alone or in combination with BM 13.177; however, the differences as compared to the nonresponders were only minor.

In vitro experiments on cyclic AMP. In control conditions $0.077 \pm 0.003 \%(n=16)$ of total $\left[{ }^{3} \mathrm{H}\right]$ adenine was incorporated into cAMP. Preincubation for $6 \mathrm{~min}$ with dazoxiben $50 \mu \mathrm{M}$, BM $13.17710 \mu \mathrm{M}$ or the combination of the two drugs did not induce any additional cAMP formation in human platelets (Fig. 8 a). Stimulation of PRP with $2 \mathrm{mM}$ AA for $5 \mathrm{~min}$, with brief mixing every min, did not induce a significant change in $\left[{ }^{3} \mathrm{H}\right]$ cAMP levels. When AA-stimulation was carried out on PRP preincubated for 1 min with BM 13.177 no changes were seen while on PRP preincubated with dazoxiben a slight $(+14.6 \%)$, but not significant, increase in $\left[{ }^{3} \mathrm{H}\right]$ cAMP level was noted as compared with the saline control; however, when AA-stimulation was carried out on PRP preincubated with both dazoxiben and BM 13.177 a significant increase $(+45 \%)$ in platelet $\left[{ }^{3} \mathrm{H}\right]$ cAMP levels was observed (Fig. $8 a$ ).

In a second series of experiments neither BM 13.17710 $\mu \mathrm{M}$ nor U46619 $2 \mu \mathrm{M}$ preincubated for 5 and $4 \mathrm{~min}$, respec-

Table I. Serum Levels of BM 13.177 and Plasma Levels of Dazoxiben (Study A)

\begin{tabular}{lll}
\hline Treatment & BM 13.177 & Dazoxiben \\
\hline & $m g / l i t e r$ & $m g / l i t e r$ \\
Dazoxiben & ND & $1.57 \pm 0.29$ \\
BM 13.177 & $6.72 \pm 1.3$ & ND \\
Dazoxiben + BM 13.177 & $6.41 \pm 0.91$ & $1.51 \pm 0.39$ \\
\hline
\end{tabular}

ND, not detectable. 


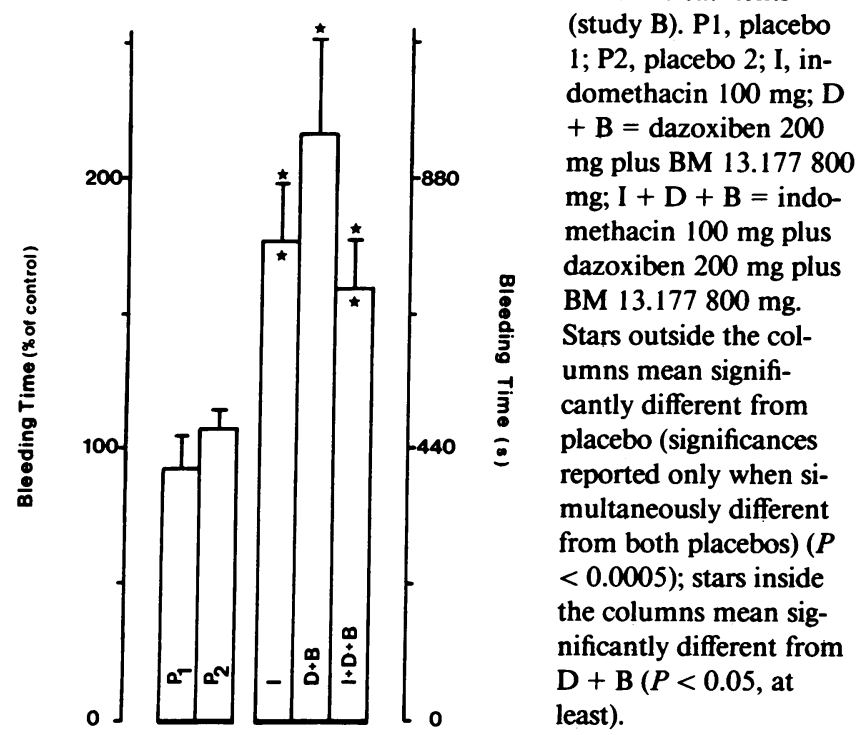

tively, significantly changed the amount of $\left[{ }^{3} \mathrm{H}\right]$ adenine incorporated into cAMP as compared to the saline-control; incubation of PRP with $\mathrm{PGD}_{2} 0.1 \mu \mathrm{M}$ for $2 \mathrm{~min}$ lead to a $228 \%$ increase in the quantity of newly formed cAMP. The addition of $\mathrm{U} 466192 \mathrm{~min}$ before $\mathrm{PGD}_{2}$ strikingly reduced the rise produced by the prostaglandin; however, preincubation with BM 13.177 restored to a large extent the cAMP-stimulatory activity of $\mathrm{PGD}_{2}$ (Fig. $8 b$ ).

\section{Discussion}

The present study shows that the combination of a thromboxane synthase inhibitor and a thromboxane receptor antagonist inhibits platelet function in vivo and ex vivo in normal humans more strikingly than either compound alone.
The cause of the stronger antiplatelet effect obtained with the combination is not a deeper suppression of $\mathrm{TXA}_{2}$ formation. The level of inhibition of $\mathrm{TXA}_{2}$ synthesis was the same after the intake of dazoxiben alone or in combination with BM 13.177. The receptor antagonist by itself, indeed, did not affect $\mathrm{TXA}_{2}$ synthesis. The slight reduction of the amount of $\mathrm{TXB}_{2}$ formed after the stimulation of PRP with AA at the TAC that was found after the intake of BM 13.177 is the consequence of the inhibition of platelet aggregation; indeed, by increasing the concentration of the stimulus, and thus partly overcoming the inhibition of platelet aggregation (10), the depressing effect on $\mathrm{TXB}_{2}$ formation disappeared. $\mathrm{TXB}_{2}$ generation by AA-stimulated platelets depends, to a great extent, on the degree of aggregation (Gresele et al., unpublished results).

A drug interaction leading to increased plasma concentrations of one or both compounds (32) was also excluded in our study by the measurement of the circulating levels of the administered drugs.

The most plausible explanation for the augmented effectiveness of a thromboxane receptor antagonist when associated to a thromboxane synthase inhibitor is, therefore, the increased formation of antiaggregatory prostaglandins $\left(\mathrm{PGD}_{2}, \mathrm{PGI}_{2}\right)$.

Although the results of capillary immunoreactive 6-ketoPGF $_{1 \alpha}$ must be interpreted cautiously in view of possible limitations of RIA 6-keto-PGF ${ }_{1 \alpha}$ measurements in blood (33), the values obtained after placebo agree with those reported very recently by other investigators using either an enzyme-linked immunoabsorbent assay (34) or gas chromatography-negative ion chemical ionization-mass spectrometry (GC-NICI-MS) (35). These data seem to indicate that the intake of dazoxiben alone or in combination with BM 13.177 results in a marked increase of $\mathrm{PGI}_{2}$ production at the level of the bleeding time wound. This increase is the likely consequence of the rediversion of the metabolism of platelet endoperoxides, accumulated after thromboxane synthase inhibition, towards $\mathrm{PGI}_{2}(5,6)$. The values obtained should be sufficient to inhibit platelet aggregation (36). After the submission of our paper a review article has appeared that reports, among other things, the de-

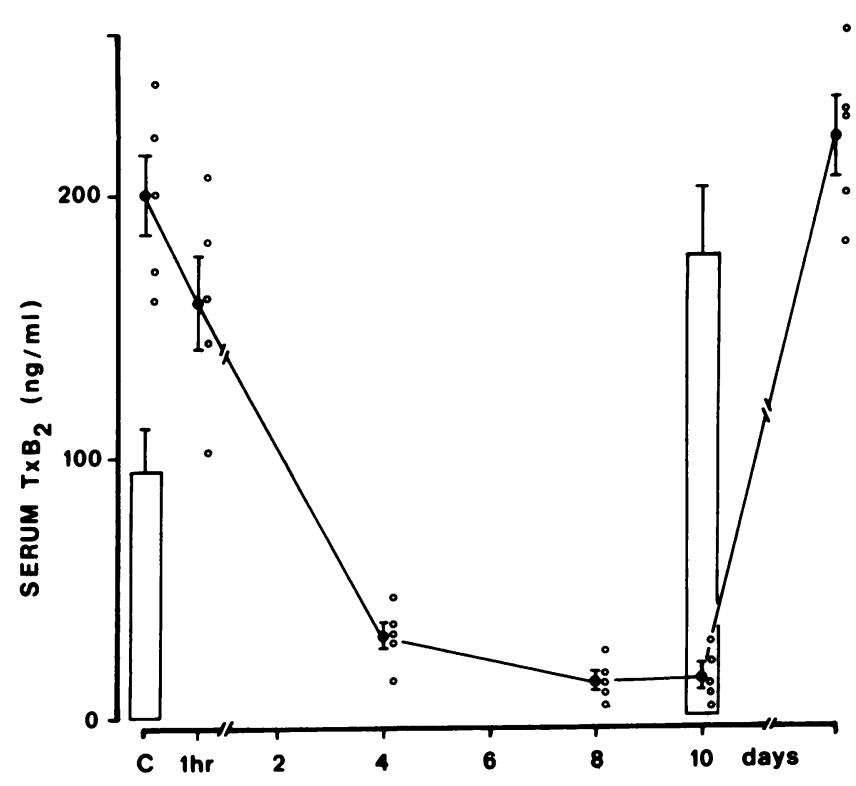

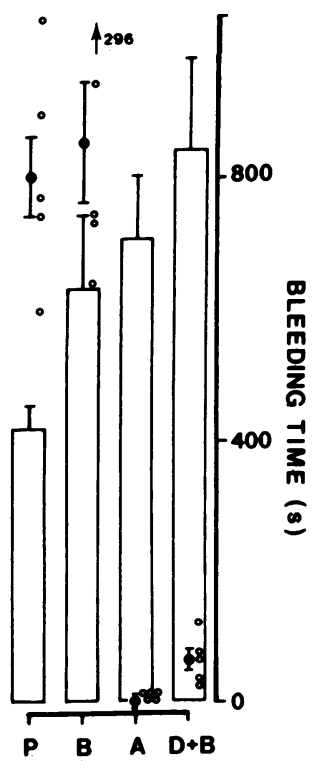

Figure 7. Serum $\mathrm{TXB}_{2}($ dots $)$ and bleeding time values (columns) during prolonged intake of low-dose aspirin $(0.43 \pm 0.02 \mathrm{mg} / \mathrm{kg}$ per d) (left); and after the intake of the following treatments: P, placebo; B, BM 13.177800 $\mathrm{mg}$; A, high-dose aspirin (500 mg p.o.) and $\mathrm{D}+\mathrm{B}=$ dazoxiben $200 \mathrm{mg}$ plus BM $13.177800 \mathrm{mg}$. C, control (basal determination). The data with low-dose aspirin and high-dose aspirin were obtained in an unblinded manner (see Methods). 


\begin{tabular}{lllll}
\hline Inducer $\ldots \ldots \ldots \ldots \ldots \ldots$ & & & U46619 & ADP \\
\hline Treatment & Collagen & AA & $\mu M$ & $\mu M$ \\
& $\mu g / m l$ & $m M$ & $0.63 \pm 0.09$ & $2.65 \pm 0.7$ \\
Basal & $1.8 \pm 0.5$ & $0.53 \pm 0.02$ & $0.55 \pm 0.07^{\ddagger}$ & $4.25 \pm 0.8^{* \ddagger}$ \\
L-ASA & $4.6 \pm 0.8^{* \ddagger}$ & $>5^{*}$ & $3.06 \pm 0.45^{*}$ & $4.1 \pm 0.9^{* \ddagger}$ \\
BM 13.177 (800 mg) & $4.2 \pm 0.6^{* \ddagger}$ & $1.49 \pm 0.5^{* \ddagger}$ & $3.20 \pm 0.51^{*}$ & $5.4 \pm 1.5^{*}$ \\
Dazoxiben + BM 13.177 & $5.8 \pm 0.4^{*}$ & $>5^{*}$ & $0.61 \pm 0.06$ & $2.45 \pm 0.5$ \\
Placebo & $1.4 \pm 0.5$ & $0.56 \pm 0.04$ & $4.54 \pm 0.46^{* \ddagger}$ & $3.9 \pm 0.8^{* \ddagger}$ \\
BM 13.177 (1,600 mg) & $4.0 \pm 0.8^{* \ddagger}$ & $4.14 \pm 0.5^{* \ddagger}$ & $0.54 \pm 0.10$ & $5.6 \pm 0.9^{*}$ \\
H-ASA & $5.0 \pm 0.4^{*}$ & $>5^{*}$ & &
\end{tabular}

L-ASA, low-dose aspirin $(0.43 \pm 0.02 \mathrm{mg} / \mathrm{kg} / \mathrm{d}$ p.o. for $10 \mathrm{~d})$; H-ASA, high-dose aspirin $(500 \mathrm{mg}$ p.o. $){ }^{*}$ Significantly different from placebo $(P$ $<0.0005)$; ' significantly different from dazoxiben + BM $13.177(P<0.01$, at least); L-ASA differed significantly from BM $13.177800 \mathrm{mg}$ when using AA and U46619 ( $P<0.0005)$; BM $13.177800 \mathrm{mg}$ differed significantly from BM $13.1771,600 \mathrm{mg}$ when using AA and U46619 $(P$ $<0.005$ ). The data with L-ASA, H-ASA, and BM 13.177 1,600 $\mathrm{mg}$ were obtained in an unblinded manner (see Methods).

tection by GC-NICI-MS of a striking increase in capillary 6keto-PGF ${ }_{1 \alpha}$ in one healthy volunteer after thromboxane synthase inhibition (37), in agreement with our findings.

We have further studied the redirection of PG endoperoxide metabolism in the PRP of our volunteers after stimulation with $\mathrm{AA}$ in vitro. We could show that, after dazoxiben intake, a striking increase in $\mathrm{PGE}_{2}$ and $\mathrm{PGD}_{2}$ is measured. Such an increase has already been detected with dazoxiben in vitro by using TLC (20), RIA (7), or GC/MS (38). The redirection of endoperoxide metabolism was evident in our study also after the intake of the combination of dazoxiben and BM 13.177, supporting our previous observation that the receptor antagonist does not hinder the capacity of a synthase inhibitor to increase the formation of a number of prostaglandins, some of which are potentially antiaggregating (19). BM 13.177 also does not interfere with the platelet inhibitory properties of $\mathrm{PGI}_{2}, \mathrm{PGD}_{2}$, or $\mathrm{PGE}_{1}$ (10).

Two additional findings corroborate the hypothesis that increased endogenous formation of antiaggregatory/vasodilating PGs is responsible for the enhanced antiplatelet effect of the combination dazoxiben plus BM 13.177. Firstly, the addition of indomethacin, at doses high enough to completely in- hibit cyclooxygenase, to the combination dazoxiben plus BM 13.177 , significantly shortened the bleeding time. Indomethacin itself prolonged the bleeding time, thus rendering a nonspecific shortening effect of this drug unlikely. The total suppression of the synthesis of cyclic endoperoxides with consequent unavailability for the formation of $\mathrm{PGD}_{2}$ and/or $\mathrm{PGI}_{2}$ appears to be the most likely explanation for the effect of indomethacin in our study. Secondly, aspirin at low-dose lead to a prolongation of the bleeding time and to an inhibition of platelet aggregation in vitro that was significantly slighter than observed after dazoxiben plus BM 13.177. Such a dose of aspirin suppresses platelet $\mathrm{TXB}_{2}$ production without significantly inhibiting urinary excretion of 6-keto-PGF ${ }_{1 \alpha}$ or 2,3dinor-6-keto- PGF $_{1 \alpha}(39,40)$, two indexes of renal and systemic $\mathrm{PGI}_{2}$ synthesis in vivo (33). This finding seems to indicate that the $\mathrm{PGI}_{2}$ produced by the vessel wall in normal conditions plays little role in primary hemostasis, but that an increased formation, as provoked by a thromboxane synthase inhibitor, may contribute to inhibition of platelet aggregation and plug formation, at least when the proaggregatory activity of cyclic endoperoxides is simultaneously antagonized.

In our studies the combination of dazoxiben plus BM

Table III. Maximal Amplitude ( $\Omega$ ) of Aggregation Induced in Whole Blood (Impedance Method) by Collagen and ADP (Study C)

\begin{tabular}{|c|c|c|c|c|c|c|c|c|}
\hline \multirow{2}{*}{$\frac{\text { Inducer . . }}{\text { Treatment }}$} & \multicolumn{4}{|c|}{ Collagen $(\mu \mathrm{g} / \mathrm{ml})$} & \multicolumn{4}{|l|}{$\operatorname{ADP}(\mu \mathrm{M})$} \\
\hline & 0.5 & 1 & 3 & 5 & 1 & 2 & 5 & 10 \\
\hline Basal & $7.5 \pm 2.2$ & $9.2 \pm 2.7$ & $12.1 \pm 1.9$ & $17.2 \pm 3.3$ & $4.8 \pm 3.2$ & $9.9 \pm 4.7$ & $18.5 \pm 4.6$ & $17.3 \pm 3.0$ \\
\hline L-ASA & $1.0 \pm 0.6^{*}$ & $3.6 \pm 1.3^{* \neq}$ & $16.3 \pm 2.1^{\ddagger}$ & $14.9 \pm 1.3$ & $1.0 \pm 0.4^{*}$ & $5.9 \pm 1.7^{*}$ & $12.9 \pm 2.4^{* \ddagger}$ & $16.0 \pm 2.9^{* \ddagger}$ \\
\hline BM 13.177 (800 mg) & $0.65 \pm 0.3^{*}$ & $3.4 \pm 1.1^{* \ddagger}$ & $15.3 \pm 5.1^{\ddagger}$ & $16.7 \pm 1.9$ & $1.6 \pm 1.3^{*}$ & $6.2 \pm 3.9^{*}$ & $11.5 \pm 3.5^{*}$ & $15.7 \pm 3.5^{* \pm}$ \\
\hline Dazoxiben + BM 13.177 & $0.5 \pm 0.5^{*}$ & $0.15 \pm 0.15^{*}$ & $10.9 \pm 0.7^{*}$ & $13.0 \pm 0.9^{*}$ & $1.2 \pm 0.9^{*}$ & $3.9 \pm 2.5^{*}$ & $8.6 \pm 2.1^{*}$ & $11.7 \pm 3.1^{*}$ \\
\hline Placebo & $7.6 \pm 2.6$ & $13.0 \pm 1.5$ & $18.4 \pm 2.5$ & $19.1 \pm 2.1$ & $4.4 \pm 3.4$ & $10.5 \pm 4.2$ & $17.7 \pm 4.1$ & $19.9 \pm 2.1$ \\
\hline BM $13.177(1,600 \mathrm{mg})$ & $0.1 \pm 0.1^{*}$ & $0.6 \pm 0.3^{*}$ & $16.8 \pm 0.7^{\ddagger}$ & $15.5 \pm 1.6$ & $1.2 \pm 0.5^{*}$ & $6.2 \pm 3.8^{*}$ & $16.2 \pm 4.0^{\ddagger}$ & $16.3 \pm 2.6^{\ddagger}$ \\
\hline H-ASA & $0.6 \pm 0.3^{*}$ & $2.1 \pm 1.6^{*}$ & $14.6 \pm 1.9$ & $14.7 \pm 1.9^{*}$ & $1.9 \pm 1.4$ & $5.6 \pm 2.0^{*}$ & $11.5 \pm 2.8^{*}$ & $17.7 \pm 3.3^{\ddagger}$ \\
\hline
\end{tabular}

L-ASA: low-dose aspirin $(0.43 \pm 0.02 \mathrm{mg} / \mathrm{kg} / \mathrm{d}$ p.o. for $10 \mathrm{~d})$; H-ASA: high-dose aspirin $(500 \mathrm{mg}$ p.o. $)$. ${ }^{*}$ Significantly different from placebo $(P$ $<0.05$, at least) (significances are reported only when simultaneously different from both basal and placebo); ${ }^{\ddagger}$ significantly different from dazoxiben $+\mathrm{BM} 13.177(P<0.05$, at least $)$. Basal and placebo were significantly different from each other for collagen 1 and $3 \mu \mathrm{g} / \mathrm{ml}$-induced platelet aggregation $(P<0.01$ and $P<0.0005$, respectively); BM 13.177 (both 800 and $1,600 \mathrm{mg}$ ) never differed significantly from low-dose aspirin. The data with L-ASA, H-ASA and BM $13.1771,600 \mathrm{mg}$ were obtained in an unblinded manner (see Methods). 
a.

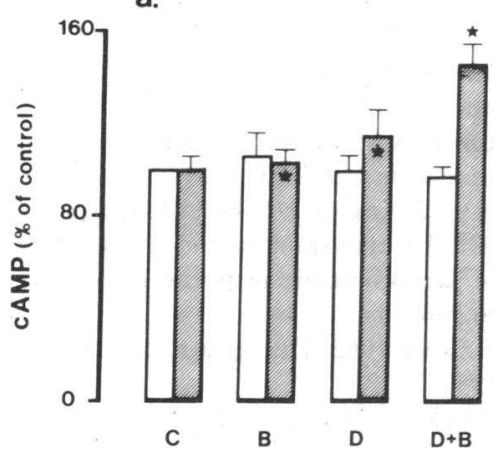

b.

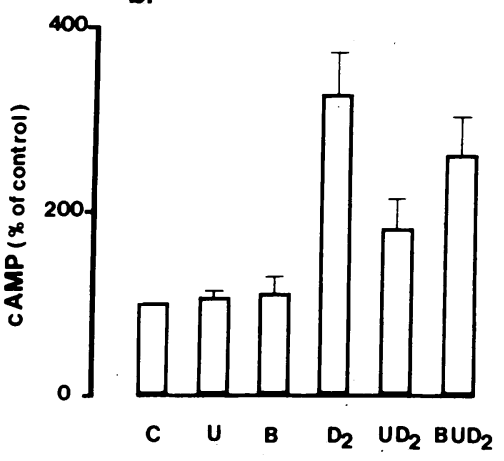

Figure 8. (a) Intraplatelet cAMP (expressed as percentage of control), after preincubation of normal PRP in vitro with $\mathrm{C}$, saline; $\mathrm{B}, \mathrm{BM}$ $13.17710 \mu \mathrm{M}$; D, dazoxiben $50 \mu \mathrm{M}$; D + B $=$ dazoxiben $50 \mu \mathrm{M}$ plus BM $13.17710 \mu \mathrm{M}$, in unstimulated platelets (open columns) and in platelets stimulated with $2 \mathrm{mM}$ arachidonic acid (hatched columns). The star outside the column indicates a significant difference as compared to control (C) $(P$ $<0.0005)$; stars inside the columns indicate significant differences as compared to the combination $(\mathrm{D}+\mathrm{B})(P$ $<0.0005$ ) (data represent mean \pm SEM of 9 experiments, each carried out in triplicate). (b) Intraplatelet cAMP (expressed as percentage of control) after preincubation of PRP in vitro with C, saline; U, U46619 $2 \mu \mathrm{M}$; B, BM $13.17710 \mu \mathrm{M} ; \mathrm{D}_{2}$, $\mathrm{PGD}_{2} 0.1 \mu \mathrm{M} ; \mathrm{UD}_{2}, \mathrm{U} 466192 \mu \mathrm{M}$ and $\mathrm{PGD}_{2} 0.1 \mu \mathrm{M} ; \mathrm{BUD}_{2}, \mathrm{BM}$ $13.17710 \mu \mathrm{M}, \mathrm{U} 466192 \mu \mathrm{M}$ and $\mathrm{PGD}_{2} 0.1 \mu \mathrm{M}$ (data represent mean \pm SEM of six experiments, each carried out in triplicate). The differences between $D_{2}$ and $C, D_{2}$ and $U D_{2}$ and $U D_{2}$ and $B U D_{2}$ were all significant $(P<0.001$, at least).

13.177, as well as low-dose aspirin, never totally suppressed $\mathrm{TXB}_{2}$ formation, different from that observed with both 100 $\mathrm{mg}$ indomethacin and $500 \mathrm{mg}$ aspirin. Indications exist that even a residual 5 to $10 \% \mathrm{TXA}_{2}$ can suffice, in particular conditions, to induce some platelet activation $(40,41)$. However, the functional significance of a small residual percentage of $\mathrm{TXA}_{2}$-synthetic capability may be greatly exaggerated when studying platelet aggregation in vitro. The half-life of $\mathrm{TXA}_{2}$, $\sim 30 \mathrm{~s}$ at $\mathrm{pH} 7.4$ in aqueous solutions at $37^{\circ} \mathrm{C}(1)$, is considerably increased in plasma (42) and this may allow the building up in the aggregometer cuvette of concentrations of this potent mediator high enough to partly activate platelets, even when cyclooxygenase is inhibited by $90-95 \%$. In vivo removal by flow and tissue metabolism could neutralize the activity of any residual $\mathrm{TXA}_{2}$ formed. Indeed, in our study no further prolongation of the bleeding time was seen when using a $500-\mathrm{mg}$ dose of aspirin as compared to a low-dose, despite a higher degree of $\mathrm{TXB}_{2}$ inhibition, and the combination of dazoxiben and BM 13.177 increased the bleeding time more than any other treatment, despite a sometimes lower degree of $\mathrm{TXB}_{2}$ suppression.

Thromboxane synthase inhibitors have been consistently shown to increase platelet $\operatorname{PGD}_{2}$ production $(9,38)$, besides inhibiting $\mathrm{TXA}_{2}$ synthesis, and despite that to exert little inhibition on platelet aggregation. We have hypothesized that accumulated endoperoxides, interacting with the shared $\mathrm{TXA}_{2} /$
PG endoperoxide receptor, would "turn off" platelet adenylate cyclase (19) in this way neutralizing the antiaggregatory effect of $\mathrm{PGD}_{2}$ and $\mathrm{PGI}_{2}$, which act precisely by "turning on" this enzyme and increasing intracellular cAMP $(15,16)$. The only product that can account for the increase in intraplatelet cAMP in normal PRP stimulated with AA in the presence of the combination of a $\mathrm{TXA}_{2}$-synthase inhibitor and a receptor antagonist is $\mathrm{PGD}_{2}$. BM 13.177, by blocking the $\mathrm{TXA}_{2} / \mathrm{PG}$ endoperoxide receptor, would neutralize the activity of endoperoxides, leaving $\mathrm{PGD}_{2}$ free to act (Fig. $8 \mathrm{~b}$ ). The cAMP increase observed in our experiments in AA-stimulated PRP (45\%) is sufficient to inhibit platelet aggregation (43). A similar increase is observed in a dose-response curve to exogenous $\mathrm{PGD}_{2}$ with around $21 \mathrm{ng} / \mathrm{ml}$ (Gresele et al., unpublished results). This amount, and even larger quantities, is normally formed in stimulated platelets with an inhibited thromboxane synthase. $\mathrm{PGE}_{2}$ can blunt the adenylate cyclase-stimulatory action of $\mathrm{PGD}_{2}$ (44).

Although the increase in cAMP observed in vitro with the combination of a thromboxane synthase inhibitor and a receptor antagonist is relatively small, this does not necessarily apply to the in vivo situation where enhanced amounts of $\mathrm{PGI}_{2}$ would also be produced: $\mathrm{PGI}_{2}$ is a much more potent adenylate cyclase stimulator than $\operatorname{PGD}_{2}(15,16)$. To the extent that the combination of a thromboxane synthase inhibitor and a thromboxane receptor antagonist results in the activation of platelet adenylate cyclase selectively at sites of enhanced platelet activation, this association might have major antithrombotic potential: an increase in platelet cAMP inhibits activation by both thromboxane-dependent and thromboxane-independent mechanisms (17).

In conclusion, our study demonstrates, for the first time in vivo in man, that prostaglandin endoperoxides can partly substitute for the activity of $\mathrm{TXA}_{2}$ and that an increased endogenous production of antiaggregatory and vasodilatory prostaglandins, such as that obtained with selective thromboxane synthase inhibition, may significantly contribute to the impairment of primary hemostasis.

Although the drug combination used in our studies is unpractical for therapeutic purposes due to the pharmacokinetic dissimilarities between BM 13.177 and dazoxiben, compounds displaying both thromboxane synthase inhibitory and receptor antagonistic properties already exist (45). Similar drugs but with a stronger potency and a longer duration of action, could turn out to be useful antithrombotic agents. Preliminary results in a coronary thrombosis model in dogs seem to support this possibility (46).

\section{Acknowledgments}

BM 13.177 tablets were kindly supplied by Dr. H. Etti, Boehringer Mannheim, Mannheim, West Germany, who also provided the determinations of BM 13.177 in serum. Dazoxiben was given by Dr. $\mathbf{H}$. Tyler, Pfizer Research, Sandwich, Kent, England, who also kindly provided the estimations of dazoxiben in plasma. The authors thank Dr. C. Patrono for helpful discussion.

\section{References}

1. Hamberg, M., J. Svensson, and B. Samuelsson. 1975. Thromboxanes: a new group of biologically active compounds derived from prostaglandin endoperoxides. Proc. Natl. Acad. Sci. USA. 72:29942998. 
2. Harker, L. A. 1986. Clinical trials evaluating platelet-modifying drugs in patients with atherosclerotic disease and thrombosis. Circulation. 73:206-223.

3. Weksler, B. B., K. Tack-Goldman, V. A. Subramanian, and W. A. Gay. 1985. Cumulative inhibitory effect of low-dose aspirin on vascular prostacyclin and platelet thromboxane production in patients with atherosclerosis. Circulation. 71:332-340.

4. FitzGerald, G. A., A. R. Brash, J. A. Oates, and A. K. Pedersen. 1983. Endogenous prostacyclin biosynthesis and platelet function during selective inhibition of thromboxane synthase in man. J. Clin. Invest. 71:1336-1343.

5. Marcus, A. J., B. B. Weksler, E. A. Jaffe, and M. J. Broekman. 1980. Synthesis of prostacyclin from platelet-derived endoperoxides by cultured human endothelial cells. J. Clin. Invest. 66:979-986.

6. Schafer, A. I., D. D. Crawford, and M. A. Gimbrone. Unidirectional transfer of prostaglandin endoperoxides between platelets and endothelial cells. 1984. J. Clin. Invest. 73:1105-1112.

7. Gresele, P., H. Deckmyn, E. Huybrechts, and J. Vermylen. 1984. Serum albumin enhances the impairment of platelet aggregation with thromboxane synthase inhibition by increasing the formation of prostaglandin $\mathrm{D}_{2}$. Biochem. Pharmacol. 33:2083-2088.

8. Bertelé, V., C. Cerletti, A. Schieppati, G. di Minno, and G. de Gaetano. 1981. Inhibition of thromboxane synthetase does not necessarily prevent platelet aggregation. Lancet. i:1057-1058.

9. FitzGerald, G. A., I. A. Reilly, and A. K. Pedersen. 1985. The biochemical pharmacology of thromboxane synthase inhibition in man. Circulation. 72:1194-1201.

10. Gresele, P., H. Deckmyn, J. Arnout, J. Lemmens, W. Janssens, and J. Vermylen. 1984. BM 13.177, a selective blocker of platelet and vessel wall thromboxane receptors, is active in man. Lancet. i:991994

11. Friedhoff, L. T., J. Manning, P. T. Funke, E. Ivashkiv, J. Tu, W. Cooper, and D. A. Willard. 1986. Quantitation of drug levels and platelet receptor blockade caused by a thromboxane antagonist. Clin. Pharmacol. Ther. 40:634-642.

12. Brittain, R. T., L. Boutal, M. C. Carter, R. A. Coleman, E. W. Collington, H. P. Geisow, P. Hallet, E. J. Hornby, P. P. A. Humphrey, D. Jack, I. Kennedy, P. Lumley, P. J. McCabe, I. F. Skidmore, M. Thomas, and C. J. Wallis. 1985. AH 23848: a thromboxane receptorblocking drug that can clarify the pathophysiologic role of thromboxane $\mathrm{A}_{2}$. Circulation. 72:1208-1218.

13. Riess, H., E. Hiller, B. Reinhardt, and C. Brauning. 1984. Effects of BM 13.177, a new antiplatelet drug in patients with atherosclerotic disease. Thromb. Res. 35:371-378.

14. Kattelman, E. J., D. L. Venton, and G. C. Le Breton. 1986. Characterization of $\mathrm{U} 46619$ binding in unactivated, intact human platelets and determination of binding site affinities of four $\mathrm{TXA}_{2} /$ $\mathrm{PGH}_{2}$ receptor antagonists (13-APA, BM 13.177, ONO 3708 and SQ 29,548). Thromb. Res. 41:471-481.

15. Gorman, R. R., F. A. Fitzpatrick, and O. V. Miller. 1978. Reciprocal regulation of human platelet cAMP levels by thromboxane $\mathrm{A}_{2}$ and prostacyclin. Adv. Cyclic Nucl. Res. 9:597-609.

16. Mills, D. C. B., and D. E. Macfarlane. 1974. Stimulation of human platelet adenylate cyclase by prostaglandin $\mathrm{D}_{2}$. Thromb. Res. 5:401-412.

17. Haslam, R. J., M. M. L. Davidson, T. Davies, J. A. Lynham, and M. D. McClenaghan. 1978. Regulation of blood platelet function by cyclic nucleotides. Adv. Cyclic Nucl. Res. 9:533-552.

18. Bertelé, V., and G. de Gaetano. 1982. Potentiation by dazoxiben, a thromboxane synthetase inhibitor, of platelet aggregation inhibitory activity of a thromboxane receptor antagonist and of prostacyclin. Eur. J. Pharmacol. 85:331-333.

19. Gresele, P., E. Van Houtte, J. Arnout, H. Deckmyn, and J. Vermylen. 1984. Thromboxane synthase inhibition combined with thromboxane receptor blockade: a step forward in anti-thrombotic strategy? Thromb. Haemostasis. 52:364.

20. Vermylen, J., G. Defreyn, L. O. Carreras, S. J. Machin, J. Van
Schaeren, and M. Verstraete. 1981. Thromboxane synthetase inhibition as antithrombotic strategy. Lancet. i:1073-1075.

21. Staiger, C., H. Patscheke, G. Neugebauer, B. Kaufmann, K. Strein, R. Endele, and K. Stegmeier. 1986. Single dose pharmacokinetics and effects on platelet function of the thromboxane receptor blocker BM 13.177. Eur. J. Clin. Pharmacol. 29:573-579.

22. Gresele, P., H. Bounameaux, J. Arnout, J. L. Perez-Requejo, H. Deckmyn, and J. Vermylen. 1985. Thromboxane $A_{2}$ and prostacyclin do not modulate the systemic hemodynamic response to cold in humans. J. Lab. Clin. Med. 106:534-541.

23. Born, G. V. R., and M. J. Cross. 1963. The aggregation of blood platelets. J. Physiol. 168:178-195.

24. Gresele, P., C. Zoja, H. Deckmyn, J. Arnout, J. Vermylen, and M. Verstraete. 1983. Dipyridamole inhibits platelet aggregation in whole blood. Thromb. Haemostasis. 50:852-856.

25. Cardinal, D. C., and R. J. Flower. 1980. The electronic aggregometer: a novel device for assessing platelet behavior in blood. $J$. Pharmacol. Methods. 3:135-158.

26. Patrono, C., G. Ciabattoni, E. Pinca, F. Pugliese, G. Castrucci, A. De Salvo, M. A. Satta, and B. A. Peskar. 1980. Low dose aspirin and inhibition of thromboxane $\mathrm{B}_{2}$ production in healthy subjects. Thromb. Res. 17:317-327.

27. Defreyn, G., H. Deckmyn, and J. Vermylen. 1982. A thromboxane synthetase inhibitor reorients endoperoxide metabolism in whole blood towards prostacyclin and prostaglandin $\mathrm{E}_{2}$. Thromb. Res. 26:389-400.

28. Levine, L., I. Alam, and J. J. Langone. 1979. The use of immobilized ligands and ${ }^{125} \mathrm{I}$ protein $\mathrm{A}$ for immunoassays of thromboxane $B_{2}$, prostaglandin $D_{2}, 13,14$-dihydro-prostaglandin $E_{2}, 5,6$-dihydroprostaglandin $\mathrm{I}_{2}$, 6-Keto-prostaglandin $\mathrm{F}_{1 \alpha} ; 15$-hydroxy-9 ${ }_{\alpha}, 11_{\alpha}$ (epoxymethano) prosta-5,13-dienoic acid and 15-hydroxy-1 $1_{\alpha}, 9_{\alpha}$ (epoxymethano) prosta-5,13-dienoic acid. Prostaglandins Med. 2:177189.

29. Krishna, G., B. Weiss, and B. B. Brodie. 1968. A simple, sensitive method for the assay of adenyl cyclase. J. Pharmacol. Exp. Ther. 163:379-385.

30. Tyler, H. M., C. A. P. D. Saxton, and M. J. Parry. 1981. Administration to man of UK-37,248-01, a selective inhibitor of thromboxane synthetase. Lancet. i:629-632.

31. Li, C. C. 1964. Introduction to Experimental Statistics. McGraw-Hill Book Co., New York. pp. 460.

32. Murad, F., and A. G. Gilman. 1985. Drug interactions. In The Pharmacological Basis of Therapeutics, VIIth Ed. A. Goodman-Gilman, L. S. Goodman, T. W. Rall, and F. Murad, editors. McMillan Publishing Co., New York. 1734-1750.

33. FitzGerald, G. A., A. K. Pedersen, and C. Patrono. 1983. Analysis of prostacyclin and thromboxane $A_{2}$ biosynthesis in cardiovascular disease. Circulation. 67:1174-1177.

34. Gerrard, J. M., J. C. Docherty, and S. Singhroy. 1986. Measurement of prostacyclin and thromboxane production in response to a standard in vivo injury in humans. 6th International Conference on Prostaglandins and Related Compounds, Florence, 3-6 June 1986, Abstr. 421.

35. Nowak, J., J. Doran, and G. A. FitzGerald. 1986. Formation of prostacyclin in vivo at a site of platelet-vessel wall interaction in man. 6th International Conference on Prostaglandins and Related Compounds, Florence, 3-6 June 1986, Abstr. 13.

36. Gresele, P., H. Deckmyn, J. Arnout, and J. Vermylen. 1984 Platelet inhibitory activity of prostacyclin in the presence of erythrocytes as studied with the impedance aggregometer. Br. J. Haematol. 57:171-173.

37. Catella, F., J. Nowak, and G. A. FitzGerald. 1986. Measurement of renal and non-renal eicosanoid synthesis. Am. J. Med. 81(Suppl. 2B):23-29.

38. Rajtar, G., C. Cerletti, M. N. Castagnoli, V. Bertelé, and G. de Gaetano. 1985. Prostaglandins and human platelet aggregation. Implications for the anti-aggregating activity of thromboxane-synthase inhibitors. Biochem. Pharmacol. 34:307-310. 
39. Patrignani, P., P. Filabozzi, and C. Patrono. 1982. Selective cumulative inhibition of platelet thromboxane production by low-dose aspirin in healthy subjects. J. Clin. Invest. 69:1366-1372.

40. FitzGerald, G. A., J. A. Oates, J. Hawiger, R. L. Mass, L. J. Roberts, J. A. Lawson, and A. R. Brash. 1983. Endogenous biosynthesis of prostacyclin and thromboxane and platelet function during chronic administration of aspirin in man. J. Clin. Invest. 71:676-688.

41. Di Minno, G., M. J. Silver, and S. Murphy. 1983. Monitoring the entry of new platelets into the circulation after ingestion of aspirin. Blood. 61:1081-1085.

42. Smith, J. B., C. Ingerman, and M. J. Silver. 1976. Persistence of thromboxane $\mathrm{A}_{2}$-like material and platelet release-inducing activity in plasma. J. Clin. Invest. 58:1119-1122.

43. Michel, H., J. P. Caen, G. V. R. Born, R. Miller, G. Angles
d'Auriac, and P. Meyer. 1976. Relation between the inhibition of aggregation and the concentration of CAMP in human and rat platelets. Br. J. Haematol. 33:27-38.

44. Bonne, C., B. Martin, M. Watada, and F. Regnault. 1981. The antagonism of prostaglandins $I_{2}, E_{1}$ and $D_{2}$ by prostaglandin $E_{2}$ in human platelets. Thromb. Res. 21:13-22.

45. Berrettini, M., M. De Cunto, P. Parise, S. Grasselli, and G. G. Nenci. 1983. Picotamide, a derivative of 4-methoxy-isophtalic acid, inhibits thromboxane synthetase and receptors in vitro and in vivo. Thromb. Haemostasis. 50:127 (Abstr. 0381).

46. Fitzgerald, D., J. Fragetta, and G. A. FitzGerald. 1985. Thromboxane synthase inhibition and thromboxane $A_{2}$ /endoperoxide receptor antagonism in a canine model of coronary thrombosis. Circulation. 72(Suppl. III):III-422 (Abstr. 1688). 